\title{
Medical students' views on the use of video technology in the teaching of isiZulu communication, language skills and cultural competence
}

\author{
P Diab, ${ }^{1} \mathrm{MB}$ ChB, MFamMed; M Matthews, ${ }^{2} \mathrm{MB} \mathrm{ChB}, \mathrm{DOH}, \mathrm{MPH} ; \mathbf{R}$ Gokool, ${ }^{3} \mathrm{BA}, \mathrm{BA}$ Hons, MA \\ ${ }^{1}$ Discipline of Rural Health, School of Nursing and Public Health, University of KwaZulu-Natal, Durban, South Africa \\ ${ }^{2}$ School of Clinical Medicine, Nelson R Mandela School of Medicine, University of KwaZulu-Natal, Durban, South Africa \\ ${ }^{3}$ Discipline of African Languages, School of Arts, College of Humanities, Howard College Campus, University of KwaZulu-Natal, Durban, South Africa
}

Corresponding author: P Diab (diabp@ukzn.ac.za)

Background. The role of communicator has been included as a key competency for health science students in South Africa. Owing to the population's diverse language and cultural backgrounds, communication between patients and healthcare professionals is challenging. In this study, the Attention, Generation, Emotion and Spacing (AGES) neurocognitive model of learning was used as a framework to create videos for language teaching for the vocational needs of students.

Objectives. To explore students' views on the use of videos of simulated clinical scenarios for isiZulu communication and language teaching and the development of cultural awareness.

Methods. Videos were developed using first- and second-language isiZulu speakers with scripts (verified by the university's Language Board) based on authentic clinical settings. Videos were shown to a target group of students, who were then interviewed in focus group discussions. Audio recordings from the discussions were transcribed and analysed thematically in three categories, i.e. communication, language skills, and cultural awareness, using deductive coding based on the objectives of the research.

Results. Students affirmed numerous benefits of the videos and commented on their use and further development. Benefits described related well to the AGES model of learning and fulfilled the learning requirements of communication teaching, language acquisition and cultural awareness.

Conclusion. The videos represent an innovative teaching method for the resource-constrained environment in which we work and are relevant to the 21 st century learner. Further evaluation and development of the tool using different scenarios and African languages is recommended.

Afr J Health Professions Educ 2016;8(1):11-14. DOI:10.7196/AJHPE.2016.v8i1.402

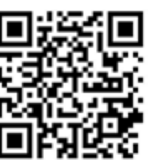

The University of KwaZulu-Natal (UKZN), Durban, South Africa (SA) has adopted a list of core competencies for medical students, derived from the Royal College of Physicians and Surgeons of Canada Physician Competencies (CanMEDS), ${ }^{[1]}$ which includes as one of its key facets the role of communicator. Some of the objectives are to develop rapport and trust between patients and healthcare providers from different cultural backgrounds, with a particular mention of respect for 'diversity and difference, including ... the impact of ethnicity, gender, religion, education and culture. ${ }^{[2]}$

Training in clinical communication at UKZN follows the CalgaryCambridge method ${ }^{[3]}$ which stresses the importance of content (what information is obtained) and process skills (how information is obtained) in a medical interview, and places emphasis on a patient-centred method in which biomedical, contextual and patient perspectives are explored. ${ }^{[4]}$ However, as a Eurocentric model, it has been suggested that the method is not useful in a multicultural and multilingual society such as SA. The authors believe that such a model can be used in the SA context by stressing the importance of the patient's perspective and the meaning that his culture brings to the consultation.

The 2011 census showed that nearly 78\% of people living in KZN speak isiZulu, one of the province's official languages, as a home language. ${ }^{[5]}$ The UKZN's bilingual language policy, approved in 2006, proposes that the university develops the use of isiZulu as a language for communication, with particular emphasis on 'professional/vocational training for undergraduate students. ${ }^{[6]}$ In a study by Matthews, ${ }^{[7]}$ the current isiZulu module for 1st-year medical students, which provides basic vocabulary and grammar skills, has been shown to be insufficient to equip students to communicate effectively with their patients in a clinical setting. Matthews recommended that a vertically integrated isiZulu course for medical students be introduced to reinforce learning, concentrating on basic interpersonal communicative skills and appropriate terminology and vocabulary for a medical interview.

Neurocognitive theory has become an important framework for planning and guiding the development of teaching material in many disciplines and has been used as such for the isiZulu video project. The Attention, Generation, Emotion and Spacing (AGES) neurocognitive model describes how hippocampal activation improves long-term retention and retrieval of learnt material. ${ }^{[8]}$ The four features of the AGES model consider the following aspects of learning: getting information into the brain and encoding it; retention of memories; and retrieval of memories. ${ }^{[8]}$ For learning to occur, full attention must be paid to the topic to be learnt, with concentrated focus on the task. Davachi et al ${ }^{[8]}$ suggest that one method of doing so is to make learning situations as authentic as possible, e.g. with the use of advanced simulations. These authors state that the generation of memories or recall is optimised when learners are able to 'contextualise, retain and apply knowledge in their own way', and that using methods which are thought to be entertaining or novel may invoke positive emotions that enhance learning. ${ }^{[8]}$ The final part of the model describes how spacing (distributing learning over time) and revisiting content lead to better longterm memory. ${ }^{[8]}$

The use of videos as an audiovisual component in second-language teaching has been shown to be successful and relevant to the needs of learners ${ }^{[9]}$ Further- 
more, videos have been demonstrated to be useful in teaching language for a specific purpose, i.e. for the vocational requirements of medical students. ${ }^{[10]}$ Other advantages of video technology in teaching communication are that it contains visual (body language) and auditory (speech patterns and rhythms) content ${ }^{[9]}$ It also has the advantage of being able to be offered on various platforms, such as learning management systems and public platforms, e.g. YouTube, at a time and place convenient to the viewer, ${ }^{[11]}$ and creates a link between theoretical teaching and its practical application.

\section{Objectives}

The general objective of the study was to explore students' views on the novel approach of using video clips as a language teaching tool in the context of the AGES model. Specific objectives were to explore how the videos improved their learning of communication skills, isiZulu language skills and awareness of the cultural context of the consultation.

\section{Methods}

The authors, being integrally involved in communication training at UKZN, identified the need to develop a means of communication teaching, where both English and isiZulu were used, which would be able to teach language and communication skills simultaneously. Where possible, scripts were developed in isiZulu by second-language speakers, relying on their experience in authentic clinical settings. These were checked for grammatial and language accuracy by an isiZulu tutor and other first-language isiZulu speakers, including the language co-ordinator of the university. The scenarios are representations of real life, although none is factual in content or person. They focus on various clinical presentations and disease entities, and use the CalgaryCambridge framework.

For the purpose of this study, only one of the videos was shown - a scenario involving a young woman who presented with lower-abdominal pain and menstrual problems, symptoms located in a cultural context of the patient to prove her fertility.

The 'patients' in the videos were actors trained in communication skills at the UKZN clinical skills department. The 'doctors' were authors and colleagues comfortable in second-language isiZulu, but with no formal training in the language at an academic level. The videos were filmed in a simulated setting by a professional videographer.

Final-year students in their Family Medicine rotation took part in the study. They were exposed to the video, and their comments with regard to communication skills, language and cultural learning were recorded in focus group discussions (FGDs) and a self-reflection questionnaire (QUEST).

Ethical permission to perform the study was granted by the UKZN Humanities and Social Sciences Research Ethics Committee (HSS/0312/013). Permission was obtained from all relevant gatekeepers and individual consent from participating students. Audio recordings of the FGDs were transcribed and thematically analysed using inductive coding with the assistance of NVivo (version 9) (USA).

\section{Results}

Responses from students with regard to the video tool were overwhelmingly positive. Only one student, who admitted to having a particularly poor understanding of isiZulu, felt that she obtained very little benefit from the video as she had not paid attention to a subject that was not examinable at the time and that she found uninteresting. In general, students embraced the idea of using technology and new learning tools to enhance learning of doctor-patient communication skills and to assist with learning of a second language. Although students were not specifically informed of the AGES model of learning, they expressed the following comments about the videos in general.

'I think the videos are actually quite good because I do not remember half the scenarios they gave us at school because they were written. You know, we are not paying attention, we dozed off, but I mean if you have seen it and remember it, I do not know, maybe it will be better.' (FGD2)

'And then if they make it available thereafter that is often a good reinforcement because it is one thing watching the video and then just going home, and then another thing watching it and then having to go over it and even watch it again when you have practised because then you actually realise how much you had forgotten though we can then pick up.' (FGD2)

'It will possibly also find ways of how to make Zulu itself interesting as a language.' (FGD2)

\section{Communication skills}

Students mentioned that they felt the videos demonstrated the importance of communication skills in terms of building the doctor-patient relationship.

'How the doctor was communicating with the patient - it is something that we are taught ... but something we overlook ... if you are watching it time and time again then you learn.' (FGD2)

They also highlighted the importance of various process and non-verbal skills important in communication teaching, which were evident in the videos.

'The encouragement.' (FGD3)

'... and eye contact.' (FGD3)

'Your expression and body language ... will determine your relationship with the patient in terms of trust.' (FGD3)

\section{Language skills}

Students generally articulated the need to be able to communicate in isiZulu with their patients.

'It automatically creates a bond between doctor and patient.' (QUEST 11)

The importance of the spoken language was highlighted.

'We will not be writing notes in Zulu in as much as we will be taking a history in Zulu. So it is the speaking part that is most important.' (FGD1)

Students thought that another advantage of the videos was the learning of vocabulary and specific keywords and phrases within a specific context. The combination of hearing words in context and being able to relate them to the written word on the scripts was found to be very useful.

'I think it is good, excellent to link it [language teaching] with video scenarios. If it is in context we can remember it better rather than getting a list of vocab.' (FGD2) 
'Common words, common questions like "When did it start?", "Where does it refer to?” ... simple things like that really would help.' (FGD3)

In addition to second-language isiZulu speakers identifying the advantages the videos could have for them, first-language isiZulu speakers felt that the videos could benefit their understanding of the language, especially in a medical context.

'I am Zulu. I am from a Zulu background. But there are certain things that I cannot explain to patients in Zulu because I do not know the terminology'. (FGD2)

\section{Enhancing cultural awareness}

Students identified another objective as enhancing cultural awareness in consultations. They related many episodes where they had been exposed to situations in which an awareness of the patient's cultural beliefs was vital to the consultation and reflected their need to improve their own cultural sensitivity.

'I think you should be teaching [cultural awareness] because it is so common. It comes up so much wherever you are.' (FGD2)

The scenario shown to students highlighted a young woman who wanted to prove her fertility to her betrothed. One student accurately summarised the meaning of the scenario portrayed:

'I think she was scared that if she does [not] have babies her husband is not going to marry her and I think the doctor acknowledged that and said she will try her best. And she did not judge her because her husband was going to leave her. She did not say what kind of husband is that who is going to leave you when you need him the most and stuff like that.' (FGD3)

\section{Technical aspects of the videos}

To develop the videos for future teaching, students were specifically asked about recommendations on technical aspects of development, utilisation and availability.

'[the video] needs to be very clear and quite slow.' (FGD3)

'Something like tutorials where students are broken into small groups and are given a scenario which two people simulate - one is a patient and the other one a doctor.' (FGD1)

'... the videos should be easily provided to the students that they can download from the website or to take home, watch on the computer and actually read the words ... that would be a much easier and faster way of learning.' (FGD1)

'To have them available on your cell phone. Oh! That would be amazing!' (FGD2)

Students debated whether the videos should have subtitles on the screen, or if a separate script, with translation, should be made available.

'If the subtitles are there you will end up focusing on them because you will end up not listening, just reading.' (FGD3)

'I think maybe the video and the printed [script]. If you have both of them you can hear how the word sounds and then you know. (FGD2)

\section{Discussion}

The main objective of this article was to present and discuss students' views on the use of video clips of simulations of authentic clinical situations to enhance communication and language skills in isiZulu and develop cultural awareness for a medical consultation in line with UKZN's Language Policy and Plan. Results of this exploratory study suggest that the use of such videos has many benefits.

Students indicated that the videos captured their attention and most expressed their interest in and enthusiasm for this teaching method. Furthermore, students of the 21 st century are technoliterate and very familiar with the use of audiovisual content, which many of them interact with and share on a daily basis. They articulated that hearing the language and observing visual cues while watching the relevant material in simulations of an authentic clinical setting would probably assist in the generation of new knowledge compared with traditional didactic teaching. The use of emotion to capture and hold a student's attention is highlighted as a trigger to make learning more interesting and relevant - a concept supported by other authors. ${ }^{[8,12]}$ The notion of spacing of content is well supported in the literature ${ }^{[8,13]}$ and by students, who remarked on the advantages of being able to revisit content on the videos as frequently as required. By revisiting and reflecting on past experiences, students are able to make meaning of what they have learnt in the preclinical years and adapt it for future use in clinical settings.

Using video technology to teach communication skills through simulated scenarios has been reported to be successful. ${ }^{[14-16]}$ However, there is not much literature on the use of videos in second-language teaching. Students sampled in our study noted that using the videos to identify and highlight process skills is particularly beneficial in a second-language context. Students became sensitised to and remarked on the effectiveness of body language in engaging the patient, and realised that a willingness to use the patient's language and simple techniques in the interview can improve the doctor-patient relationship and interaction.

Students highlighted the importance of being able to listen to isiZulu as a spoken language, which would benefit them in learning pronunciation and specific keywords and phrases for their context. Second-language teaching places much emphasis on listening and speaking compared with writing or reading the language. Video technology has been shown to be very effective for this purpose. ${ }^{[9,17]}$ Moreover, the use of audiovisual media to enhance pronunciation, especially with regard to vocational-specific learning, has been documented in other international studies. ${ }^{[18,19]}$ Of particular interest was that first-language isiZulu speakers felt they would also derive learning from exposure to the videos, especially with regard to medical terminology.

In addition to the teaching of language skills, the videos provided a valuable opportunity for sensitising students to cultural influences in a medical consultation. Part of understanding the patient's perspective involves an appreciation of the patient's life-world, which includes his understanding, cultural beliefs and past personal experiences. ${ }^{[20]}$ Students indicated that an awareness of their patients' cultural perspectives will contribute to a shared understanding of concepts in the consultation and its outcome.

\section{Study limitations}

As this was an exploratory study, it is limited in nature. Only one video clip was shown to final-year students in the Family Medicine rotation. No formal evaluation has been conducted yet, although such plans are in place for 2014. (These evaluations have been commenced, but are still ongoing at 
the time of publication.) With regard to the use of the video in the learning environment, it has been noted that a basic knowledge of the isiZulu language and some technical ability are essential.

\section{Recommendations}

Owing to much interest and enthusiasm that this study has generated among students, the videos were presented to other role players including the Medical Students Representative Committee, Information and Communication Technology Services, language experts and members of the College of Health Sciences, UKZN. As a consequence of engagement with these role players, it was decided to formally include the series of videos in the curriculum. We have suggested that further research in implementing and evaluating the use of videos as a resource to enhance teaching and learning in the programme is undertaken. Additional funding should be made available for the development of the project. It is hoped that this study will trigger dissemination of the teaching tool to various disciplines, schools and other institutions in SA.

\section{Conclusion}

The value of teaching isiZulu as a second language in vocational training is not disputed and communication skills have become a core competency of health education. Because of current resource limitations, innovative teaching methods are required to deliver the necessary content. Learning should also be relevant to the 21 st century learner in a format that triggers an emotive and lasting response in the brain. The use of recorded, simulated representations of authentic clinical scenarios to fulfil these requirements requires further investigation and evaluation.

\section{References}

1. Frank JR, Danoff D. The CanMEDS initiative: Implementing an outcomes-based framework of physician competencies. Med Teach 2007;29(7):642-647. [http://dx.doi.org/10.1080/01421590701746983]

2. Health Professions Council of South Africa (HPCSA). Core Competencies for Undergraduate Students in the Clinic Associate, Dentistry and Medical Teaching and Learning Programmes in South Africa. Pretoria: HPCSA, 2012. 3. Silverman J, Kurtz S, Draper J. Skills For Communicating with Patients. 2nd ed. London, UK: Radcliffe Publishing, 2005.

4. Kurtz S, Silverman J, Benson J, Draper J. Marrying content and process in clinical method teaching: Enhancing the Calgary-Cambridge guides. Acad Med 2003;78(8):802-809.

5. Statistics SA. Census 2011 - The languages of South Africa, 2011. http://www.southafrica.info/pls/procs/iac (accessed 8 April 2013).

6. University of KwaZulu-Natal. Language Policy and Plan of the University of KwaZulu-Natal. Durban: UKZN, 2013.

7. Matthews M. Vocation-specific isiZulu Language Teaching and Learning for Medical Students at the University of KwaZulu-Natal. Durban: UKZN, 2013

8. Davachi L. Kiefer T, Rock D, Rock L. Learning that lasts through AGES. NeuroLeadership Journal 2010;3:53-63.

9. Canning-Wilson C, Wallace J. Practical aspects of using video in the foreign language classroom. Internet TESL Journal 2000;6(11):36-1.

10. Belcher DD. Trends in teaching English for specific purposes. Ann Rev Appl Linguistics 2004;24:165-186.

11. Topps D, Helmer J, Ellaway R. YouTube as a platform for publishing clinical skills training videos. Acad Med 2013;88(2):192-197. [http://dx.doi.org/10.1097/ACM.0b013e31827c5352]

12. LeDoux JE. Emotion, memory and the brain. Sci Am 1994;270(6):50-57.

3. Litman L, Davachi L. Distributed learning enhances relational memory consolidation. Learn Mem 2008;15(9):711-716.

14. Hurtubise L, Martin B, Gilliland A, Mahan J. To play or not to play: Leveraging video in medical education. J Grad Med Educ 2013;5(1):13-18. [http://dx.doi.org/10.4300/JGME-05-01-32]

15. Fertleman C, Gibbs J, Eisen S. Video improved role play for teaching communication skills. Med Educ 2005;39(11):1155-1156. [http://dx.doi.org/10.1111/.j.1365-2929.2005.02283.x]

16. Seif GA, Brown D. Video-recorded simulated patient interactions: Can they help develop clinical and communication skills in today's learning environment? J Allied Health 2013;42(2):e37-e44.

17. Levy M. Technologies in use for second language learning. Modern Language Journal 2009;93(s1):769-782. 18. Al-Jarf R. Online videos for specific purposes. J Educ Social Res 2012;2:17-21.

19. Cakir I. The use of video as an audio-visual material in foreign language teaching classroom. Turkish Online Educ Technol 2006;5(4)

20. Candlin S, Roger P. Communication and professional relationships in healthcare practice. Equinox 2013:201 